\title{
OS RESPIRADORES QUE GANHARAM CORPOS NA ESCOLA
}

\author{
RESPIRATORS THAT WERE BODIES AT SCHOOL
}

Francisco de Paulo D'Avila Júnior ${ }^{1}$

\begin{abstract}
Resumo: O presente artigo propõe uma reflexão teórica sobre uma prática artístico-pedagógica, realizada em escolas públicas, e que promoveu uma performatividade corporal diferente no contexto de sala de aula. Para auxiliar nesta reflexão, do ponto de vista da prática realizada, fotos e relatos dos estudantes serão utilizados. Se soma a discussão, conceitos e ideias sobre as pesquisas de Michel Foucault, Gilles Deleuze e Félix Guattari acerca da ideia de corpo, e outros desdobramentos de suas obras. Na prática intitulada Respiradores, os estudantes experimentaram uma outra possibilidade de ser e de estar na escola.
\end{abstract}

Palavras-chave: Corpo; arte-educação; sustentabilidade.

\begin{abstract}
This article proposes a theoretical reflection on an artistic-pedagogical practice, carried out in public schools, which promoted a different body performance in the classroom context. To assist in this reflection, make a point of view of the practice performed, photos and reports of students will be used. The discussion, concepts and ideas on the research of Michel Foucault, Gilles Deleuze and Félix Guattari on the idea of the body are added, and other developments of their works. In the practice entitled Respirators, students experienced another possibility of being and being in school.
\end{abstract}

Keywords: Body; art education; sustainability.

\section{Prólogo}

\author{
Quando eu me encontrava preso na cela de uma cadeia \\ Foi que eu vi pela primeira vez as tais fotografias \\ Em que apareces inteira, porém lá não estavas nua \\ E sim coberta de nuvens... \\ (Terra, 1975, Caetano Veloso).
}

Esse trecho, forte e potente da música Terra de Caetano Veloso, que narra o momento em que o artista preso durante a ditadura militar brasileira, recebe na cadeia as recentes imagens da Terra, parece apontar o sentimento de deslumbre que tomou a população mundial em 1968. Com a ajuda do foguete Saturno V SA-503, os astronautas do voo espacial histórico Apollo 8, realizaram a primeira viagem em torno da Lua, que durou seis dias e atingiu a órbita do satélite. A busca por um novo lugar no espaço resultou, a partir dessas fotografias, na descoberta do nosso próprio habitat. Ao percorrer o mundo, as imagens constataram a simplicidade da beleza do nosso planeta, através das curvas e do azul potente. Embora, entre os processos biológicos e humanos, exista tamanha complexidade.

Enquanto a Terra era fotografada pelos astronautas, aqui embaixo, em paralelo com a Corrida Espacial, os seres humanos se reunião em diversas partes do mundo para discutir os rumos do planeta e a iminente incapacidade de sustentação da vida, levando em conta a acelerada degradação do meio ambiente. Com o avanço do desenvolvimento tecnológico, desde a Revolução Industrial ocorrida no final do Século XVIII, a exploração acelerada das riquezas naturais, implicou impactos dramáticos na saúde e no equilíbrio ecológico do planeta. Com o

\footnotetext{
${ }^{1}$ Universidade Católica de Brasília, Brasília, DF, Brasil.
} 
rápido progresso da ciência e tecnologia, o ser humano aumentou sua capacidade de transformar, de muitas formas, e em escalas jamais vistas, o meio natural em que vive.

Uma das discussões mais importantes da atualidade é a Sustentabilidade, e a necessidade de uma nova interação dos seres humanos com o mundo, preservando e convivendo em harmonia com o meio ambiente. Para que o modo de vida dos humanos seja considerado Sustentável, é necessário que ele seja ecologicamente correto, economicamente viável, socialmente justo e culturalmente diverso. Nas últimas décadas houve uma ampliação do debate público sobre o tema, mas com poucos avanços consideráveis. A urgência em debater e colocar em prática alternativas eficientes e capazes de sustentar o planeta, se torna evidente quando pensamos o rápido crescimento populacional e as recentes catástrofes ambientais que aconteceram ao redor do globo.

\section{Introdução}

Numa tentativa de fazer refletir, de alertar e conscientizar os estudantes sobre questões ligadas ao meio ambiente, nasceu o projeto Respiradores. Nesta experiência de coautoria, e através da construção de respiradores naturais, os estudantes são convidados a criar, refletir, performar e construir conhecimentos sobre Sustentabilidade e meio ambiente. O presente artigo propõe uma reflexão teórica sobre essa prática artístico-pedagógica, realizada em escolas públicas, e que promoveu, além do debate do tema, uma performatividade corporal diferente no contexto de sala de aula.

O projeto foi realizado pela primeira vez em abril de 2018, na Escola Municipal de Ensino Fundamental Silvina Gonçalves, em Arroio Grande, extremo sul do Rio Grande do Sul. Também aconteceu na Escola Estadual de Ensino Fundamental Rio de Janeiro, em agosto de 2018, em Porto Alegre/RS e na Escola Estadual de Ensino Fundamental Pedro Oscar Selbach, em dezembro de 2018, na cidade de Canela/RS. A prática com estudantes do Ensino Fundamental I e II, se configurou em três etapas: debate sobre o tema, a construção dos respiradores e a experiência artística

Com o projeto Respiradores, desenvolvido em diferentes escolas e cidades do Rio Grande do Sul, se percebeu a potência dos corpos dos estudantes na construção e efetivação do conhecimento proposto e vivenciado. Para auxiliar nesta reflexão, do ponto de vista da prática realizada, fotos e relatos dos estudantes serão utilizados. Se soma a discussão, conceitos e ideias sobre as pesquisas de Michel Foucault, Gilles Deleuze, Félix Guattari acerca da ideia de corpo, e outros desdobramentos de suas obras.

\section{Ganhando corpo}

Hoje, respirar em Nova Déli, na Índia, equivale a fumar 50 cigarros por dia. A poluição atmosférica, com a inserção no meio ambiente, de substancias tóxicas, prejudica a qualidade de vida, e ameaça um dos atos mais importantes para a existência, o ato de respirar. O oxigênio é envenenado pelos poluentes, em sua maioria provenientes de fontes artificiais, e produzidos pelas atividades humanas. Segundo dados da Organização Mundial de Saúde (OMS) todos os anos, a poluição do ar causa a morte de aproximadamente 7 milhões de pessoas no mundo, matando mais que AIDS e malária juntas. Se respirar é condição sine qua non, o projeto que se propõe a construir respiradores naturais e portáteis, promove o alerta necessário.

O projeto começou a ganhar corpo no momento em que os materiais necessários para construir os respiradores foram sendo reunidos. Para construir esses respiradores, se faz necessário os seguintes materiais: garrafas pet de 5lts e 200ml, máscaras, mangueiras transparentes, terra, água e plantas. Alguns materiais são reaproveitáveis, como é o caso das 
garrafas pet, mas outros precisam ser adquiridos como é o caso das máscaras de oxigênio. $\mathrm{O}$ mecanismo é construído a partir do encaixe desses materiais, que é feito pelo próprio estudante durante a realização do projeto em sala de aula.

Nas primeiras horas do encontro, se estabelece um momento de debate que envolve os estudantes e professores de outros componentes curriculares. Nesta etapa se valoriza o caráter interdisciplinar do projeto, que reúne outros saberes na construção de conhecimento sobre o tema proposto. Nesse momento é realizada uma contextualização histórica, biológica, filosófica, geográfica e artística, com momentos de compartilhar informações e escutando o que os alunos já sabiam sobre a temática. Na figura 1, um dos momentos de debate com os estudantes:

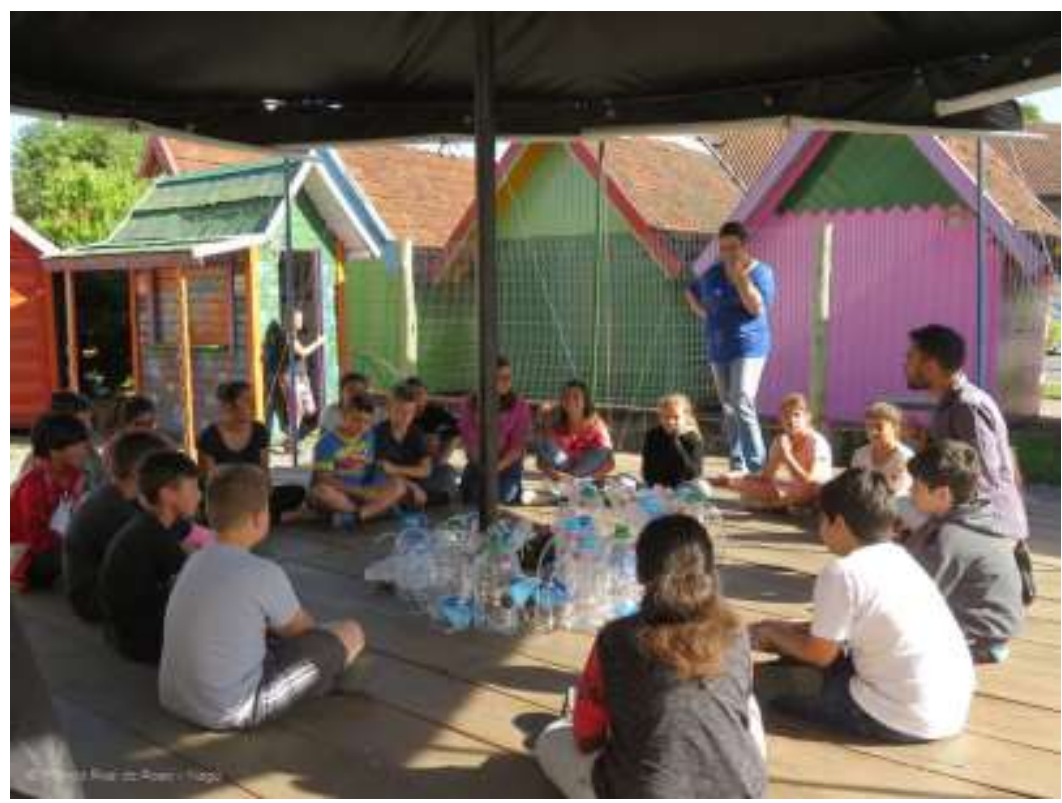

Figura 1- Registro da prática na E. M. E. F Pedro Oscar Selbach, Canela/RS. 2018 - Fonte: Marcia Rosi da Rosa

Logo após o debate, a construção da performance pedagógica avança com o início da montagem dos respiradores. Cada estudante recebe os materiais necessários para a montagem do mecanismo. No primeiro momento um espaço para conhecer os matérias, e em seguida o momento de transformar a garrafa vazia em um pequeno ecossistema, com a terra, com a planta e com a água. Nesta etapa, se valoriza a criatividade, e os estudantes podem utilizar outros elementos, como pedras, folhas, etc. Esse processo de montagem se dá em vários espaços da escola, como a sala de aula, o pátio, salas multidisciplinares, e de arte.

O oxigênio é liberado na atmosfera, graças ao processo de fotossíntese, em que organismos como algas e plantas utilizam gás carbônico para sintetizar seu próprio alimento, e durante o processo, liberam oxigênio no meio. Desvendando processos biológicos, munidos dos materiais necessários, e com mediação do professor artista, os próprios alunos montam seus mecanismos de produção de oxigênio. Primeiro a terra é colocada no fundo da garrafa pet de 5lts, e na sequência a planta é inserida. O orifício aberto na lateral da garrafa, e que serviu para colocar a terra e a planta é lacrado com plástico transparente. Outro orifício pequeno é aberto no topo, e que serve para encaixar a garrafinha menor contendo água, e que libera sistematicamente gotas na terra e na planta. Por fim, resta conectar a engenhoca na máscara de oxigênio através de mangueiras finas e transparentes. Na figura 2, observamos o respirador no processo de montagem: 


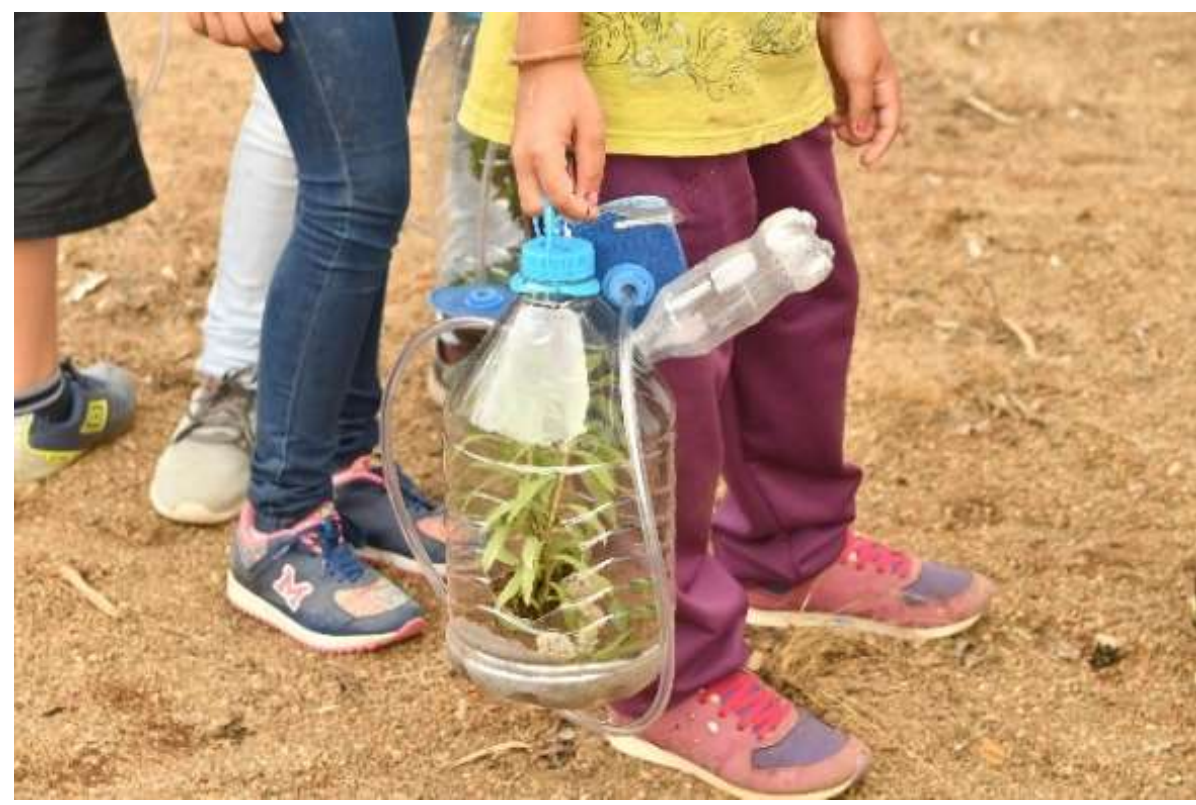

Figura 2 - Registro da prática na E. M. E. F Silvina Gonçalves, Arroio Grande/RS. 2018 Fonte: Lutierry Haubmman

O respirador vai se construindo na medida em que todo o suporte é montado para abrigar a planta, que é o elemento mais importante de toda a estrutura. A partir da interação e construção do objeto artístico, houve um estudo por parte de cada estudante sobre o modo de se relacionar com o que viria a ser uma extensão do corpo de cada um. $\mathrm{O}$ acoplamento entre corpo-respirador é experimentado ainda em sala de aula. São realizados exercícios de experimentação, como segurar, perceber o peso que o respirador tem, e também interações solitárias e em grupo. Um momento de extrema importância, visto que a próxima etapa se configura exatamente na apresentação pública desses respiradores, nas ruas do entorno da escola. Na figura 3, o aluno experimentando seu mecanismo na sala de aula.

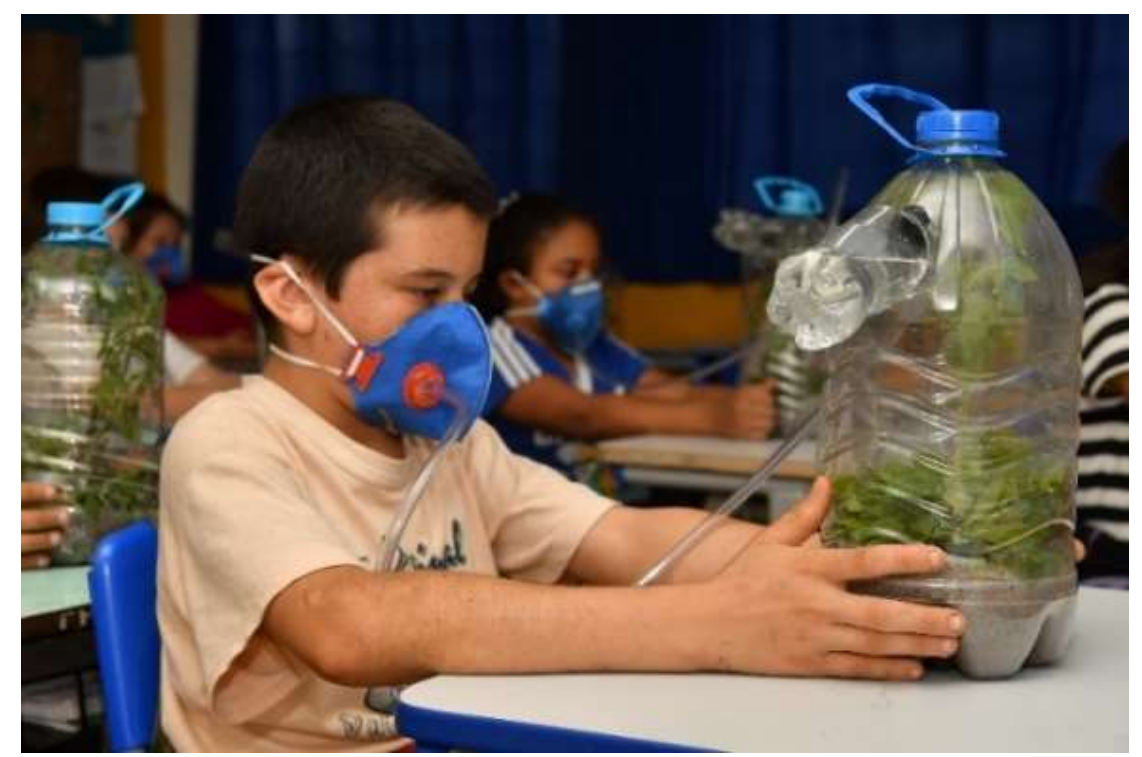

Figura 3 - Registro da prática na E. M. E. F Silvina Gonçalves, Arroio Grande/RS. 2018

Fonte: Lutierry Haubmman 
Na terceira e última etapa, depois de cada estudante ter construído e experimentado o seu respirador, todos juntos, se dirigem em coro para uma caminhada silenciosa no entorno da escola. Neste momento, o debate construído extrapola os muros e vai até a comunidade local através da intervenção artística. O professor artista guia os estudantes pelas ruas, realizando microações como atravessar o sinal, sentar nos bancos da praça, ir na parada de ônibus, etc. Outros professores, e funcionários também participam, acompanhando o corpo coletivo de alunos que se desloca pela cidade. Nas figuras 4 e 5, registros das apresentações:

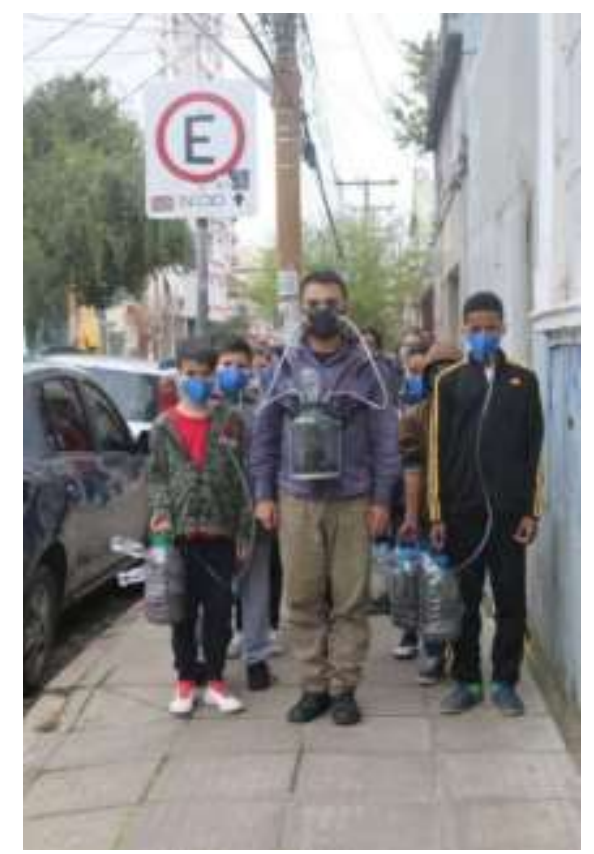

Figura 4 - Registro da prática na E. M. E. F Rio de Janeiro, Porto Alegre/RS. 2018

Fonte: Byan de Lacerda Monteiro

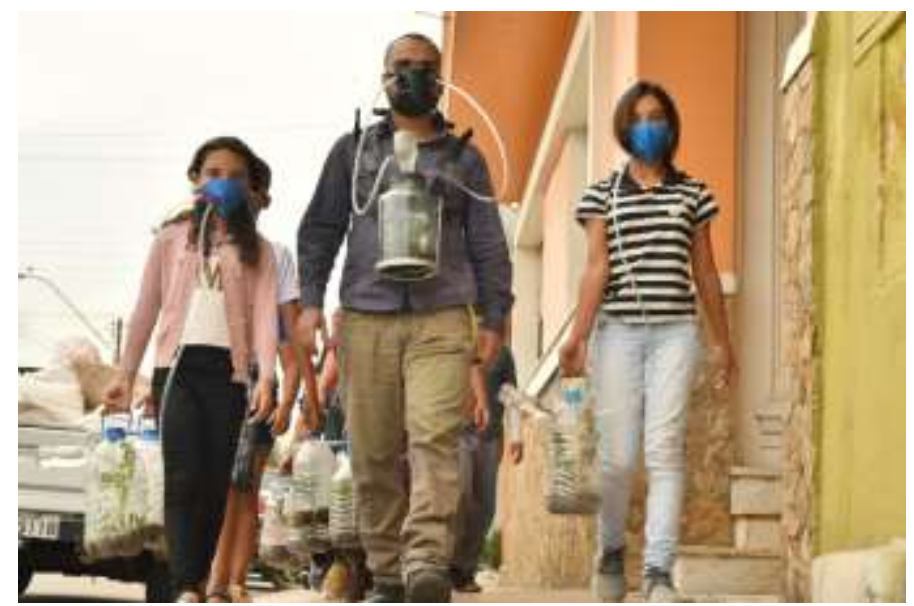

Figura 5 - Registro da prática E. M. E. F Silvina Gonçalves, Arroio Grande/RS. 2018

Fonte: Lutierry Haubmman

Embora o cortejo seja silencioso, os estudantes são orientados a interagir, caso ocorressem abordagens durante o trajeto. E alguns diálogos sempre acontecem entre os estudantes e os transeuntes. Com essa possibilidade de os estudantes vivenciarem a experiência artística, o trabalho os coloca numa posição diferente, daquelas que cotidianamente o ambiente escolar oferece. Na última edição realizada, na E.E.E.F Pedro Oscar Selbach, na cidade de 
Canela/RS, o trabalho teve a cobertura da RBS TV, que posteriormente transmitiu a matéria nos Telejornais Bom dia Rio Grande e Jornal do Almoço. Na Figura 6, é possível ter acesso à matéria completa, basta apontar a câmera do celular para o QR Code abaixo:

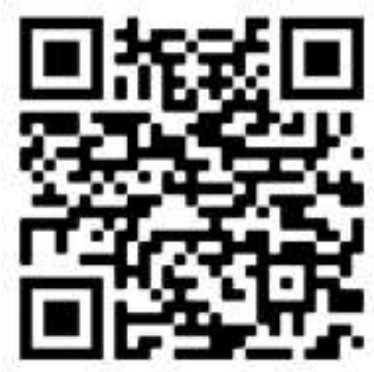

Figura 6 - Qr Code da Matéria da RBS TV - Fonte: Acervo do artista

\section{Agenciamento de forças}

\subsection{Corpo na escola}

$\mathrm{Na}$ contemporaneidade, a sociedade vive intensas crises no seio da família e das instituições. E a escola, como parte importante dessa estrutura, também sofre as consequências de uma ruina dos valores morais, éticos e a deterioração das relações humanas. A educação e a escola funcionam como mecanismos de controle, regimes e processos de normatização dos corpos e das subjetividades dos sujeitos que a compõe. Michel Foucault teorizou essa crise entre disciplina e controle, sendo Vigiar e Punir uma referência importante na complexificação do tema. Para Foucault, a sociedade disciplinar concentra corpos e gestos, tornando o corpo produtivo e dócil. Nesse aspecto, surge a comparação entre escola e presídio, no que se refere a aplicação de tecnologias disciplinares.

Os historiadores vêm abordando a história do corpo há muito tempo. Na história da humanidade o corpo esteve em diversos momentos em posição de extrema violência no que concerne o trabalho forçado, a punição, o castigo, a tortura e todos os outros procedimentos com objetivos de correção. É certo, que na contemporaneidade, com uma certa estabilidade das leis, os modos de controle e docilidades dos corpos foram, de alguma forma, remodelados. Porém, de forma mais suave ou não, ainda extremamente presentes. E é importante lembrar, que é sempre do corpo que se trata:

Mas podemos sem dúvida ressaltar esse tema geral de que, em nossas sociedades, os sistemas punitivos devem ser recolocados em uma certa "economia política" do corpo: ainda que não recorram a castigos violentos ou sangrentos, mesmo quando utilizam métodos "suaves" de trancar ou corrigir, é sempre do corpo que se trata - do corpo e de suas forças, da utilidade e da docilidade delas, de sua repartição e de sua submissão. (FOUCAULT, 1999, p. 28).

O corpo pode ser observado a partir de processos biológicos, das patologias, das necessidades fisiológicas. Todavia, o corpo também está mergulhado num campo político. $\mathrm{O}$ caráter político do corpo, está associado aos processos econômicos, "e sua constituição como força de trabalho só é possível se ele está preso num sistema de sujeição" (FOUCAULT, 1999, p. 29). Essa sujeição nem sempre acontece de forma direta, opressiva e violenta, pode muito bem ser organizada, sutil e calculada. No ambiente escolar, a fabricação de corpos docilizados, 
submissos e úteis, foi se solidificando ao longo dos tempos, principalmente no que tange as práticas pedagógicas desenvolvidas.

Por diversas vezes o corpo é neutralizado, seja pelos "tabus" que carrega socialmente, seja pela estrutura rígida que o ambiente escolar é formatado. Existem diversas formas de interditar os corpos dos estudantes, desde a hierarquia, passando pela disciplina, pelos testes de conhecimento, e também na repressão desses corpos de expressarem sua sexualidade, seus desejos, e sua participação política na sociedade. Visto que cada vez mais, a ruina desta estrutura é percebida na sala de aula, pela falta de interesse e indisciplina dos alunos, outras possibilidades precisam ocupar as brechas e promover alternativas que escapem a qualquer controle.

A escola, tal qual conhecemos, sempre operou numa perspectiva da instrumentalização, da padronização, dos procedimentos técnicos, regrados e pelo raciocínio lógico. Sendo incapaz de ensinar a pensar de uma outra forma que não seja o pensamento ordinário. Uma escola que funciona a partir da repetição, do treino, e da resolução de problemas, por diversas vezes, distantes da realidade dos estudantes, recusa-se a reconhecer os corpos, os desejos, os sentimentos e a sensibilidade como fatores importantes dentro do ensino-aprendizagem. Respiradores trata-se de uma performance pedagógica que tem o corpo como suporte para a criação. Essa prática propõe uma fuga da estratificação na qual os estudantes são submetidos, numa configuração de organização extrema, que determina o que somos, o que devemos ou não fazer, o que pensar e como sentir.

\subsection{O respirador como uma extensão do corpo}

Neste trabalho, o corpo ganha destaque ao sair das cadeiras enfileiradas e experimentarem outras possibilidades. No conceito de corpo pleno, há pelo menos três tipos de imagem do corpo que Deleuze-Guattari criam em Anti-Édipo, segundo Machado:

O primeiro toma emprestado um critério biológico, para o qual há corpo onde há organismo humano. [...] O segundo uso também esposa a biologia, e admite como corpo tudo onde há organismo. Desde o teu corpo até um micróbio. [...] Há um terceiro uso, que encontra um corpo onde há uma solidez, uma consistência - uma cadeira, uma sala, um prédio são corpos -[...] Diz-se de um livro em construção que o livro está ganhando corpo. Corpo então designa solidez, consistência, concretude. (MACHADO, 2011, p. 5):

Constata-se aí a brincadeira com o título deste texto: os respiradores que ganharam corpos na escola. Sim, levando em conta que há corpo onde há solidez, os respiradores ganharam corpos. Todavia, o título brinca com outro significado também, o que diz respeito aos estudantes que ganharam corpos ao participarem do projeto. Toda a estrutura da escola está voltada para a sistematização também dos corpos dos que a compõem. Está performatividade diferenciada que a performance proporcionou pode ser percebida no bilhete marcante do aluno Raphael: "Participar de uma experiência artística foi demais. Nós saímos com os nossos respiradores que nós mesmos fizemos, e eu nunca vou esquecer esse dia".

A prática em questão, provoca um outro corpo. Um corpo de resistência contra as formatações opressoras, se colocando de forma mais ativa, política e orgânica no mundo. Por isso, vale pensar essa prática a partir da ideia de Corpos sem Órgãos de Deleuze-Guattari. CsO aparece primeiro na obra de Antonin Artaud, e depois reativado por Gilles Deleuze e Félix Guattari (sobretudo, no Anti-Édipo e no Mil Platôs). Levando em consideração, que para os autores, o CsO "não é uma noção, um conceito, mas antes uma prática, um conjunto de práticas" 
(DELEUZE; GUATTARI, 2012, p. 12), o que interessa, acerca destes corpos em desconstrução, é que algo se passa neles.

Respiradores promove um novo agenciamento de forças, impulsos, capazes de criar um corpo pleno poderoso em contexto de sala de aula. Ter um CsO é estar desconstruindo o corpo de uma forma ativa, despertar seus devires, retirá-lo de sua inércia. Essas potências, são ativadas principalmente na conjunção com outros corpos. E na prática em questão, isto acontece em duas esferas. A primeira diz respeito ao acoplamento que acontece entre corpo-respirador e corpoestudante. Nessa relação de atravessamentos, ao realizar a prática, cada corpo descobre suas particularidades e singularidades. E a outra trata do corpo coletivo, que é o conjunto de estudantes que formam a sala de aula. Esse corpo grande, vivo, que ao se deslocar pela escola e pelas ruas das cidades acaba por criar uma infinidade de devires.

O respirador que o estudante utiliza, passa a operar como um órgão externo, como uma extensão do corpo, e com uma funcionalidade sem a qual não pode ser. Esse órgão, mesmo sendo adjacente, de todo modo, atravessa esse corpo físico pois "tudo é corpo e corporal. Tudo é mistura de corpo e no corpo, encaixe, penetração. Tudo é física, como diz Artaud:" (DELEUZE, 1974, p. 90). A imagem profética que a utilização do respirador trás, provoca o estudante a sair de uma perspectiva superficial e da superfície das coisas, e o convida para explorar as profundezas, voltar ao corpo para libertá-lo dos automatismos.

\subsection{Desejo pela produção de conhecimento e ativismo}

A participação dos estudantes nunca foi obrigatória, visto que o projeto valoriza o desejo pela produção de conhecimento. Esse desejo poderia ser posto em xeque se a prática tivesse esse caráter de obrigatoriedade. Isso é importante para se distanciar de um modo operativo decadente proposto pelo ambiente escolar. Isso vai de encontro ao pensamento do filósofo Luiz Fuganti: [...] em se desvencilhar do paradigma da educação vigente e rastrear a produção do desejo intensivo, de um pensamento afirmativo, [...] cuja força dominante é a capacidade de criar a própria condição da experiência" (FUGANTI, 2008, p. 06).

O tom da proposta foi sempre um convite para descoberta. E até agora, nas três vezes, com mais de 60 estudantes que participaram, não houve nenhuma recusa ou indisposição na realização da prática. Pensando sobre os conceitos "produção desejante" e "produção social" de Deleuze-Guattari, consideramos este trecho do livro Anti-Édipo:

A arte utiliza frequentemente essa propriedade, criando verdadeiros fantasmas de grupo que curto-circuitam a produção social com uma produção desejante, e introduzem uma função de desarranjo na reprodução de máquinas técnicas. (DELEUZE; GUATTARI, 2010, p. 49).

Se a escola está formatada perante as características de uma produção social, cabem propostas artísticas que irrompam possibilidades e que possam ativar os desejos nos estudantes. E isso fica claro, quando observamos o bilhete da aluna Emanuelly: "Eu me senti interessada porque eu achei legal". E o bilhete da aluna Luiza: "Eu gostei bastante de sair da rotina, gostei de mexer na terra, sair na rua, as pessoas perguntando, eu adorei como as pessoas reagiram da gente com aquela máscara, adorei o projeto”.

Um dos impulsos que motivaram a realização deste trabalho, além de discutir o tema da sustentabilidade, era propor uma outra possibilidade de ser e de estar na escola. Sobretudo, promover a dimensão política do processo de ensino-aprendizagem. Nesse ponto, identifico duas instâncias dessa abordagem. A primeira aborda a formação de uma afetividade em relação 
ao meio ambiente. Durante a montagem dos respiradores, e através do manejo das plantas, os corpos se movimentam na construção dessa afetividade importante e desejada. E que foi relatada pela aluna Tuane, meses após a realização da proposta na escola: "Eu achei muito bom, adorei seu projeto professor, é muito interessante. Tenho até hoje o respirador com a planta".

Já a segunda instância, diz respeito ao engajamento dos estudantes na luta por um meio ambiente mais justo e equilibrado. Quando todos saem de suas cadeiras, fabricam seus instrumentos de ativismo e vão para as ruas, a dimensão política do processo de ensinar e aprender realiza o seu ciclo. Respiradores é uma proposta que busca garantir um direito que é constitucional. Em 1988, com a Constituição da República Federativa do Brasil, o Estado brasileiro inovou ao dedicar um capítulo próprio ao direito ao meio ambiente. Trata-se do Capítulo VI do Título VIII - que diz:

Todos têm direito ao meio ambiente ecologicamente equilibrado, bem como de uso comum do povo e essencial à sadia qualidade de vida, impondo-se ao Poder Público e à coletividade o dever de defendê-lo e preservá-lo para as presentes e futuras gerações (Art. 225, caput).

O processo de tomada de consciência do perigo da devastação do meio ambiente, e o reconhecimento da diversa riqueza ecológica do país, finalmente aparecem refletidos em um capítulo da Constituição, na medida em que se reconhece o direito ao meio ambiente e também o dever coletivo de o proteger para as gerações futuras. No entanto, mesmo assegurado pela Constituição, o Direito Ambiental vem sendo constantemente violado no Brasil, seja pelo descompromisso da iniciativa privada, acarretando acidentes ambientais graves como a morte do Rio Doce em Mariana em 2015, ou por Emendas à Constituição, propostas por Governos e que são consideradas retrocessos ambientais.

\section{Conclusão}

A Terra caminha ao encontro de sua própria degradação, com o aquecimento climático, com a exploração demasiada de seus recursos naturais, com o avanço de uma lotação populacional, com a extinção de muitos de seus animais e, pelas mãos dos humanos, sua excessiva poluição. Respiradores se configurou como uma ferramenta de sensibilização e conscientização sobre o nosso papel na construção de novas interações com o meio ambiente. Percebe-se o impacto da atividade, nos registros escritos dos alunos após a conclusão do trabalho.

Este projeto busca engajar estudantes e profissionais das escolas com ações e reflexões que possam transformar a sua realidade. A ideia é incentivar os estudantes a acreditar na sua capacidade de engajamento e ativismo e também no poder de mobilização que possuem. Duas invocações foram estimuladas, trazendo diante dos olhos a dimensão profética e solidária de uma nova concepção de mundo. A imagem futurista, um fragmento de uma realidade não tão distante, é codificada e transformada em instrumento político, e que acoplado ao corpo do estudante, promove a participação política dos mesmos na sociedade.

Com todos os ciclos do projeto realizados, pode-se dizer que não só os respiradores ganharam corpos, mas os estudantes também. Desde o convite feito pelo professor artista, a prática rompeu com a sistemática da escola, tirou os alunos das cadeiras enfileiradas e promoveu uma outra performatividade na sala de aula. A performance se constrói enquanto ferramenta de ativação dos corpos, das intenções, dos desejos dos estudantes, uma estratégia para a autonomia e uma criação para a descoberta. Toda a experiência de conhecimento deveria passar pelo corpo, deveria ser sentida e percebida. 
Este trabalho continua sendo desenvolvido em escolas públicas, abrindo margem para outras possíveis reflexões, principalmente no que se refere aos impactos causados pela pandemia da Covid-19 e aos novos contornos subjetivos e críticos que o projeto ganha.

\section{Referências}

BRASIL. Constituição da República Federativa do Brasil de 1988. Disponível em: http://www.planalto.gov.br/ccivil_03/constituicao/constituicao.htm. Acesso em: 10 de jan. de 2021.

DELEUZE, G. Lógica do Sentido. Tradução de Luiz Roberto Salinas Fortes. São Paulo: Perspectiva, 1974.

DELEUZE, G.; GUATTARI, F. Mil platôs. Capitalismo e Esquizofrenia. Tradução de Suely Rolnik. São Paulo: Editora 34, 2012.

DELEUZE, G. GUATTARI, F. O Anti-Édipo. Tradução de Luiz B. L. Orlandi. São Paulo: Editora 34, 2010.

FUGANTI, Luiz. Educação para Potência (aulas 1-8). Transcrição das aulas: Renata Mello. 2008. Disponível em: http://escolanomade.org/pensadores-textos-e-videos/fugantiluiz/educacao-para-a-potencia-8-aulas-transcritas. Acesso em: 20 jan. 2021.

MACHADO, B. Deleuze e o conceito de corpo. Revista Garrafa, Rio de Janeiro, v. 24, n. 24, p. 1-11, maio-agosto de 2011.

\section{Sobre ao autor}

Francisco de Paulo D'Avila Júnior. Professor-artista-pesquisador licenciado em Teatro pela Universidade Federal de Pelotas/BR com mobilidade acadêmica no curso Estudos Artísticos da Universidade de Coimbra/PT. Atualmente cursa especialização em Direitos Humanos pela Universidade Católica de Brasília (UCB). É professor de artes efetivo da Secretaria Estadual de Educação de Minas Gerais.

E-mail: davilafrancesco@gmail.com. 